\title{
ENHANCEMENT OF A UASB-SEPTIC TANK PERFORMANCE FOR DECENTRALISED TREATMENT OF STRONG DOMESTIC SEWAGE
}

\author{
Nidal Mahmoud \\ Institute of Environmental and Water Studies (IEWS), Birzeit University, P.O. \\ Box 14, Birzeit, the West Bank, Palestine
}

\begin{abstract}
The possibility of enhancing the process performance of the UASB-septic tank for treating strong sewage in Palestine by the means of inoculating the reactor with well adopted anaerobic sludge and/or adding a packing media to the upper part of the reactor, thus becoming an AH-septic tank, was investigated. To achieve those objectives, two community onsite UASB-septic tank and Anaerobic Hybrid (AH)-septic tank were operated in parallel at 2 days HRT for around eight months overlapping the cold and hot periods of the year, Palestine. The achieved removal efficiencies of CODtot in the UASB-septic tank and AHseptic tank during the first months of operation, coinciding the cold period and the subsequent months coinciding the hot periods were respectively "50(15) and 48(15)" and "66(8) and 54.73(7.9)". This shows that the UASB-septic tank performed significantly better $(p<0.05)$ than the AH-septic tank after rather long period of operation. The difference in the CODtot removal efficiency was mainly due to the better CODss removal efficiencies in the UASBseptic tank. The removal efficiencies over the last 50 days of operation for CODtot, CODsus, CODcol and CODdis were "70, 72, 77 and 55\%" and "53, 54, 78 and 45\%" for the UASBseptic tank and AH-septic tank, respectively. Comparing the here achieved COD removal efficiencies with previously reported efficiencies of UASB-septic tanks operated in Palestine shows that the reactor performance has improved substantially by being started with well adopted anaerobic sludge but not by adding a packing media.
\end{abstract}

\section{KEYWORDS}

Decentralised; sewage; UASB; Septic tank; Anaerobic hybrid

\section{INTRODUCTION}

Decentralised wastewater treatment and disposal is practiced world wide to provide adequate wastewater management systems particularly in rural and remote human settlements [1]. Anaerobic reactors are mostly found as inherent parts of the decentralised treatment schemes due to process simplicity and low operational cost. The septic tank had been used for onsite sewage pre-treatment since more than 130 years. A significant improvement of the septic tank was achieved last two decades by applying upward flow and gas/solids/liquid separation device at the top, which resulted in the so called UASB-septic tank reactor. The reactor is operated in an upflow mode as a UASB reactor resulting in both improved physical removal of solids and improved biological conversion of dissolved components [2]. It was firstly investigated for the onsite sewage treatment at Dutch and Indonesian ambient conditions [3-

https://doi.org/10.15626/Eco-Tech.2010.038 
5]. Recently, the system has also been investigated for sewage treatment in Palestine by operating in parallel two UASB-septic tanks at 2 and 4 days HRT over a year $[1,6]$. In Palestine, and some other Middle Eastern countries like Jordan, sewage is characterised with high COD concentrations exceeding sometimes $1500 \mathrm{mg} / \mathrm{L}$ with high fraction of CODss (up to $70-80 \%$ ). In addition, sewage is characterised with temperature fluctuation between 15 and $25^{\circ} \mathrm{C}$ during the cold and hot periods of the year, which is a typical characteristic of the Mediterranean climate [7, 8].

The reactors operated in Palestine achieved moderate results in terms of CODtot removal efficiencies which exceeded 50\%, but the VFA and CODdis removal efficiencies were negligible and frequently negative in both reactors. For instance during the hot half of the year the VFA and CODdis in the effluent of the reactor operated at 4 days HRT were respectively 160 and $304 \mathrm{mgCOD} / 1$ [6]. Those values are noticeably high when compared with the VFA and CODdis in the effluent of a conventional UASB reactor operated in Jordan of respectively 10 and $210 \mathrm{mg} \mathrm{COD} / 1$, during the hot season [8]. Moreover, the effluent anaerobic biodegradability of the both reactors operated in Palestine were respectively 42 and 39\% resembling $225 \mathrm{mgCOD} / \mathrm{L}$ and $192 \mathrm{mgCOD} / \mathrm{L}$ indicating that the reactors can achieve further treatment [6]. It is not clear if the high CODdis and VFA in the effluent of both reactors were due to low sludge activity and/ or due to poor contact between influent wastewater and sludge as a consequence of low upflow velocity and low biogas production.

The enhancement of sludge bed methanogenic activity by inoculating the reactor with well adopted sludge might further improve the reactors performance. In fact, reactor start-up is very important process step and particularly the quality of the seed sludge, microbial diversity and activity, is very important for successful start - up and might be essential for advancing reactor stability and performance [9, 10]. Álvarez et al. [11] emphasized the need for conducting more research on the start-up of pilot and full-scale anaerobic digesters for the moderately cold weather countries. In addition to inoculation of the UASB-septic tank with well adopted sludge, the reactor performance might be improved by being modified to an Anaerobic-Hybrid (AH)-septic tank. The AH- septic tank consists of a sludge bed in the lower part and an anaerobic filter in the upper part, thus combines advantages of a UASB and AF reactors while minimising their limitations $[12,13]$.

The main goal of this research was to asses the possibility of enhancing the process performance of the UASB-septic tank for treating strong sewage in Palestine by (1) adding a packing media to the upper part of the reactor, thus converting the UASB-septic tank to an AH-septic tank; and (2) by inoculating the reactors with well adopted anaerobic sludge. To achieve those objectives, a UASB-septic tank and AH-septic tank reactors were operated in parallel under ambient conditions in Palestine at HRT of 2 days for eight months covering the cold and hot periods of the year.

\section{METHODS}

\subsection{Experimental set-up}


Table 1. Characteristics of the RPF sheets used in the AH-septic tank reactor

\begin{tabular}{lll}
\hline Parameter & Unit & Value \\
\hline Total sheet thickness & $\mathrm{mm}$ & 25 \\
Knob thickness & $\mathrm{mm}$ & 15 \\
Base thickness & $\mathrm{mm}$ & 10 \\
Specific surface area & $\mathrm{m}^{2} / \mathrm{m}^{3}$ & 500 \\
Pore size & $\mathrm{mm}$ & 2.5 \\
\hline
\end{tabular}

Two pilot scale UASB-septic tank and AH-septic tanks were installed and operated in parallel at the main sewage treatment plant (STP) of Al-Bireh city/ Palestine. Each of the reactors was made of galvanized steel with a working volume of $0.8 \mathrm{~m}^{3}$ (height $2.50 \mathrm{~m}$; diameter $0.638 \mathrm{~m}$ ). Nine sampling ports were installed along each of the reactors at $0.25 \mathrm{~m}$ for sludge sampling, with the first port at $0.15 \mathrm{~m}$ from the bottom of the reactors. The influent was distributed in the reactors through polyvinyl chloride (PVC) tube with 4 outlets located $5 \mathrm{~cm}$ from the bottom of the reactors. Biogas was passed through a $16 \% \mathrm{NaOH}$ solution for $\mathrm{CO}_{2}$ scrubbing, and then methane quantity was continuously measured by wet gas meters. The media used in the AH-septic tank was reticulated polyurethane foam (RPF) sheets (type Filteren TM 10 from Recticel, Buren, The Netherlands) of $72 \mathrm{~cm}$ length oriented vertically in the top of the AH-septic tank above the solids - gas separator. Each sheet had knobs at one side, while the other side was flat. The characteristics of the used RPF sheets are presented in Table 1. The sheets were installed by fixing every two sheets back to back on a metal sheet amid. 10 metal sheets were used with 20 RPF sheets. Schematic diagram of the experimental set-up is presented in Figure 1.

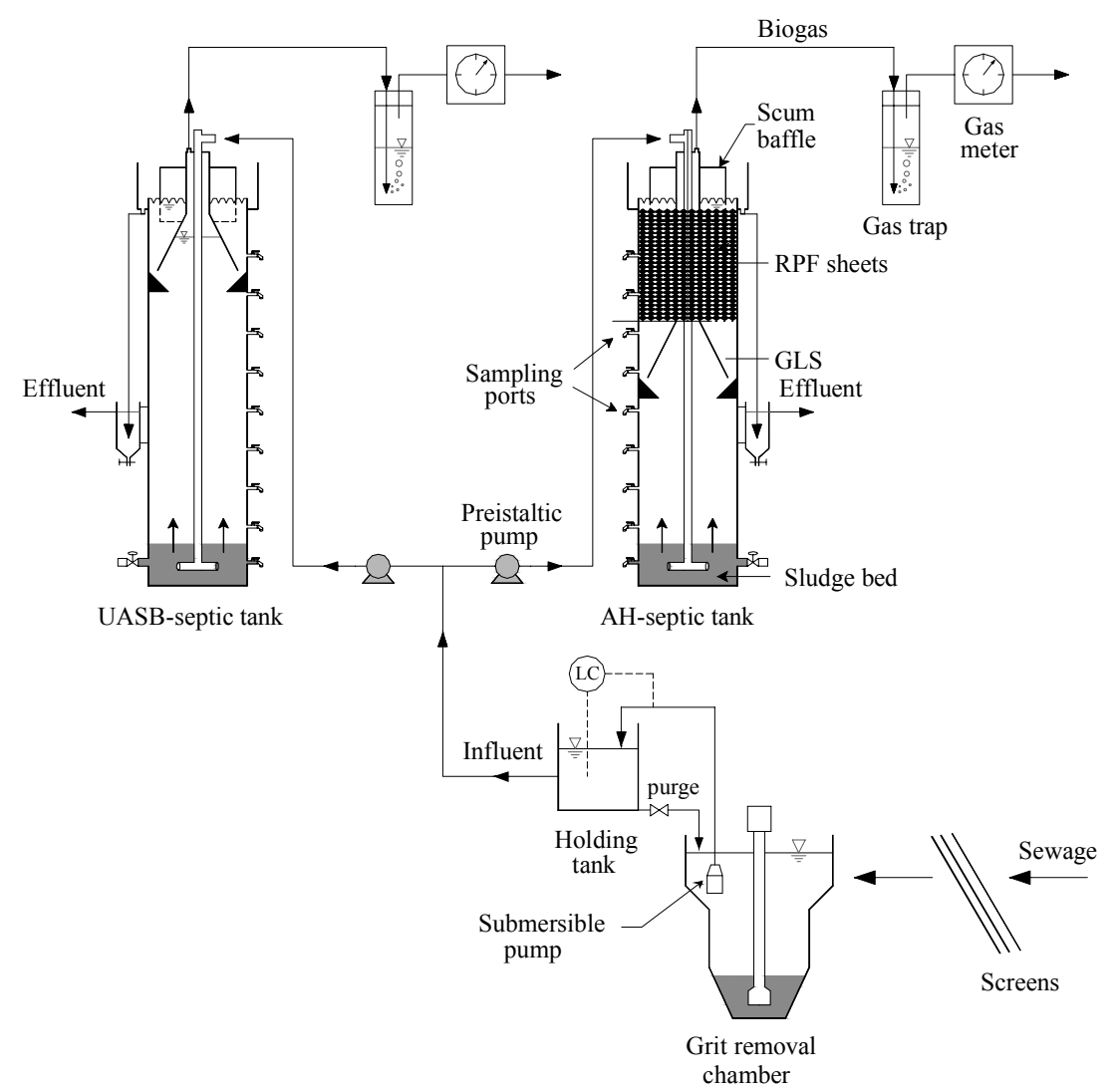

Figure 1. Schematic diagram of the experimental set-up (not to scale). GLS = Gas-liquidsolids separator; $L C=$ Level controller 


\section{Pilot plants start-up, operation and monitoring}

The UASB-septic tank and AH-septic tank were started up in January, the coldest month in the year, and operated in parallel for a period of around eight months. The reactors were operated at ambient temperature fed with domestic sewage pre-treated with screens and grit removal chamber. The sewage was pumped every five minutes to a holding tank $(200 \mathrm{~L}$ plastic container), with a resident time of about 5 minutes, where the reactors were fed and the influent was sampled. The reactors were inoculated with 50 litres of anaerobic sludge (TS: 43 g/L; VS: 29g/L; VS/TS: 67) obtained from two pilot scale UASB-septic tank reactors (50\% from each reactor) operated at 2 and 4 days HRT at the same research site and fed with sewage from the same source as in this research for more than one and a half year. Daily monitoring was started since the onset of the experiment including wastewater and ambient temperature and biogas production measurements. Grab samples of raw sewage and reactors effluents were collected and analysed two to three times a week $(1 \mathrm{~L}$ for each) for CODtot. Over the last 50days of operation, the reactors influent and effluent were analysed six times for CODtot and fractions (CODsus, CODcol, CODdis), VFA, ammonia, phosphate and faecal coliform. The atmospheric pressure was measured in situ.

\subsection{Analytical methods}

Total solids (TS), volatile solids (VS), ammonium $\left(\mathrm{NH}_{4}^{+}\right)$, Chemical Oxygen Demand (COD), Biological Oxygen Demand (BOD) and dissolved $\mathrm{PO}_{4}{ }^{3-}-\mathrm{P}$ were measured according to standard methods [14]. Raw samples were used for measuring total COD (CODtot), $4.4 \mu \mathrm{m}$ folded paper-filtered (Schleicher and Schuell 5951/2, Germany) samples for paper filtered COD (CODp) and $0.45 \mu \mathrm{m}$ membrane - filtered (Schleicher and Schuell ME 25, Germany) samples for dissolved COD (CODdis). The suspended COD (CODsus) and colloidal COD (CODcol) were calculated as the difference between CODtot and CODp and the difference between CODp and CODdis, respectively. The volatile fatty acids (VFA) analysis was carried out as described by Buchauer [15]. All samples were analysed in duplicate except VFA in single. Sludge stability was measured once in triplicate after three months of staring up the reactors as described by Mahmoud [16].

\subsection{Calculations}

\section{Nomenclature}

$\mathrm{COD}_{\text {tot }}$ : amount of total COD in the tested sample (mg COD/l)

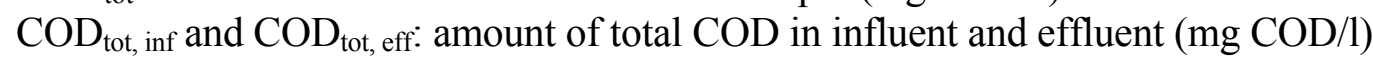

$\mathrm{COD}_{\mathrm{dis}}$, inf and $\mathrm{COD}_{\mathrm{dis}}$, eff: amount of dissolved COD in influent and effluent (mg COD/l)

$\mathrm{COD}_{\mathrm{VFA}}$, inf and COD $\mathrm{VFA}$, eff: amount of VFA in influent and effluent (mg VFA as COD/1)

$\mathrm{COD}_{\mathrm{CH} 4}$ : amount of produced $\mathrm{CH}_{4}$ (liquid form + gas form) $\left(\mathrm{mg} \mathrm{CH}_{4}\right.$ as $\left.\mathrm{COD} / 1\right) ; \mathrm{CH}_{4}$ (liquid form) was calculated according to Henry's law assuming $70 \%$ of the biogas is $\mathrm{CH}_{4}$

$\mathrm{COD}_{\text {accumulated: }}$ amount of accumulated COD in the reactor $(\mathrm{mg} / \mathrm{l})$

\section{Sludge stability}

Stability $(\%)=100\left(\mathrm{COD}_{\mathrm{CH} 4} / \mathrm{COD}_{\text {tot, } \mathrm{t}=0 \text { days }}\right)$

(1)

or

Stability $(\%)=100\left(\mathrm{COD}_{\text {tot, } \mathrm{t}=0 \text { days }}-\mathrm{COD}_{\text {tot }, \mathrm{t}=\mathrm{t} \text { days }}\right) / \mathrm{COD}_{\text {tot }, \mathrm{t}=0 \text { days }}$ 
Percentage of hydrolysis (H), acidification (A) and methanogenesis (M) were calculated according to equations 3,4 and 5 , respectively.

$$
\begin{aligned}
& \mathrm{H}(\%)=100\left(\frac{\mathrm{COD}_{\mathrm{cH} 4}+\mathrm{COD}_{\text {dis, eff }}-\mathrm{COD}_{\text {dis, inf }}}{\mathrm{COD}_{\text {tot}}, \text { inf }-\mathrm{COD}_{\text {dis, inf }}}\right) \\
& \mathrm{A}(\%)=100\left(\frac{\mathrm{COD}_{\mathrm{CH} 4}+\mathrm{COD}_{\mathrm{VFA}}, \text { eff }-\mathrm{COD}_{\mathrm{VFA}} \text {,inf }}{\mathrm{COD}_{\mathrm{tot}, \text { inf }}-\mathrm{COD}_{\mathrm{VFA}}, \text { inf }}\right) \\
& \mathrm{M}(\%)=100\left(\frac{\mathrm{COD}_{\mathrm{CH} 4}}{\mathrm{COD}_{\mathrm{tot}, \mathrm{inf}}}\right)
\end{aligned}
$$

\section{Statistical data analysis}

Statistical comparisons of means was followed by "Paired samples t-test" for the measured parameters of the two reactors using the SPSS program for windows- Release 11.0.0, SPSS ${ }^{\circledR}$ Inc. (2001), with $p$ value $<0.05$ considered significantly different.

\section{RESULTS AND DISCUSSION}

\subsection{Sewage characteristics}

The results of sewage characteristics presented in Tables 2 and 3 confirm that sewage in Palestine is characterised with high concentration of pollutants as compared with sewage characteristics in several European, Asian and Latin American countries [7, 17]. The high sewage strength in Palestine is postulated to low water consumption and people's habits [7]. The influent COD was mainly in the suspended form followed by dissolved then colloidal of respectively $65 \%, 25.8 \%$ and $9.2 \%$ (see Table 3 ). Around $40 \%$ of the influent dissolved COD was in the VFA form. The CODtot concentration during winter was less than during summer most likely due to dilution with rainwater. The mean CODtot over the whole period of operation was $1081 \mathrm{mg} / \mathrm{l}$. the sewage temperature was in the range of 2 to $4{ }^{\circ} \mathrm{C}$ lower than the ambient air temperature.

\subsection{Organic loading rate}

The reactors were operated at a rather low organic loading rate of $0.54 \mathrm{gCOD} / 1 . \mathrm{d}$ during the whole period of operation. The organic loading rate during the cold period was relatively lower than during the hot period of respectively 0.52 and $0.57 \mathrm{gCOD} / 1 . \mathrm{d}$.

\subsection{Removal efficiency}

The results presented in Figure 2 and Table 2 reveal that the UASB-septic tank and AH-septic tank have both performed equally well with no significant difference $(p>0.05)$ during the first three months of operation coinciding the winter period. During the subsequent period, coincinding the hot period, the UASB-septic tank reactor achieved significantly $(p<0.05)$ higher CODtot removal efficiencies as compared to the AH-septic tank reactor. This is attributed mainly to the rather higher fraction of suspended COD in the AH-septic tank effluent as presented in Table 3. 


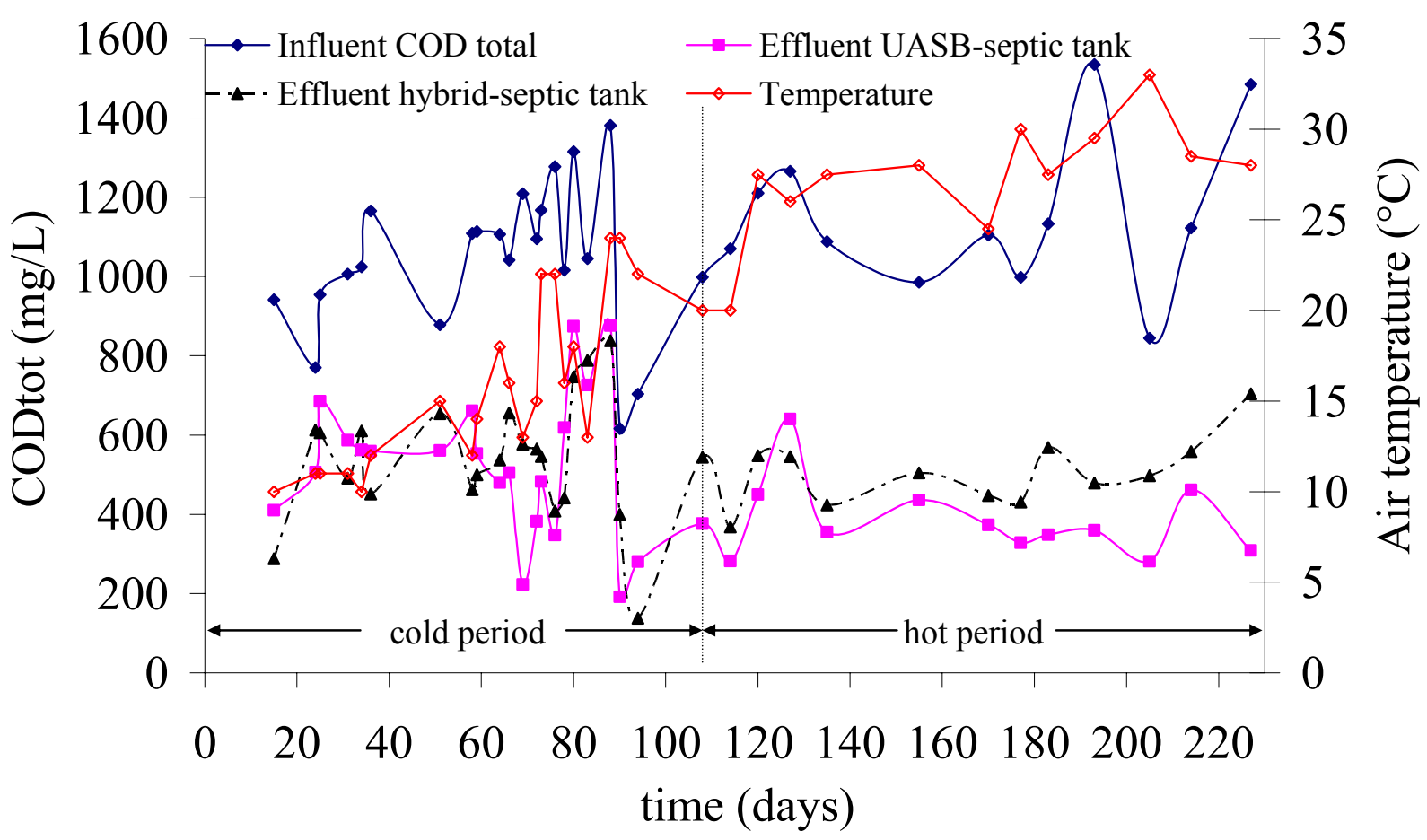

Figure 2. Influent and effluent CODtot and air temperature during the anaerobic treatment of domestic sewage from Al-Bireh City/Palestine in a UASB-Septic tank and an AH-septic tank. 0 day stands for $8^{\text {th }}$ of January

The achieved CODcol and CODdis removal efficiencies in both reactors were relatively high with no significant difference $(p>0.05)$. The rather low VFA concentration in the effluent of both reactors indicates good methanogenic conditions in both of them (see Table 3). 
Table 2. Influent and effluent CODtot and removal efficiencies (\%) during anaerobic sewage treatment in a UASB-septic tank and an AH-septic tank operated in Palestine

\begin{tabular}{|c|c|c|c|c|c|c|c|}
\hline & & \multicolumn{3}{|c|}{ First period of operation (Cold period) } & \multicolumn{3}{|c|}{ Long period of operation (Hot period) } \\
\hline & & \multicolumn{3}{|c|}{ From day 15 to day 108} & \multicolumn{3}{|c|}{ From day 108 to day 227} \\
\hline & & \multicolumn{3}{|c|}{$\mathrm{n}=22$} & \multicolumn{3}{|c|}{$\mathrm{n}=13$} \\
\hline & & Influent & UASB-Septic tank & $\begin{array}{l}\text { AH-Septic } \\
\text { tank }\end{array}$ & Influent & UASB-Septic tank & $\begin{array}{l}\text { AH-Septic } \\
\text { tank }\end{array}$ \\
\hline CODtot (mg/L) & Average & $\begin{array}{l}1042.23 \\
(187.6)\end{array}$ & $520.41(182.5)$ & $539.05(158.3)$ & 1141.27(194.9) & $384.63(96.2)$ & $509.04(84.6)$ \\
\hline \multirow{3}{*}{$\begin{array}{l}\text { CODtot removal } \\
(\%)\end{array}$} & range & $616-1381$ & $192-876$ & $138-838$ & $845-1535$ & $282-640$ & $368-704$ \\
\hline & Average & & $50.07(14.7)$ & $47.87(15.1)$ & & $65.78(8.2)$ & $54.73(7.9)$ \\
\hline & range & & $28-82$ & $21-80$ & & $49-79$ & $41-69$ \\
\hline Tair $\left({ }^{\circ} \mathrm{C}\right)$ & $\begin{array}{l}\text { Average } \\
\text { range }\end{array}$ & $\begin{array}{l}15.86(4.7) \\
10-24\end{array}$ & & & $\begin{array}{l}26.92(3.7) \\
20-33\end{array}$ & & \\
\hline
\end{tabular}


Table 3. Influent and effluent characteristics and removal efficiencies (\%) in a UASB-septic tank and an AH-septic tank treating domestic sewage in Palestine under ambient conditions. Results are average values of 6 samples measured over a 50 days period during the period 177227 days of starting the reactors

\begin{tabular}{|c|c|c|c|c|c|}
\hline \multirow{3}{*}{ Parameter } & \multirow{3}{*}{$\begin{array}{c}\text { Influent } \\
\text { concentration }\end{array}$} & \multicolumn{2}{|c|}{$\begin{array}{c}\text { UASB-septic tank } \\
(\text { HRT }=2 \text { days })\end{array}$} & \multicolumn{2}{|c|}{$\begin{array}{l}\text { AH-septic tank } \\
(\text { HRT }=2 \text { days })\end{array}$} \\
\hline & & $\begin{array}{c}\text { Effluent } \\
\text { concentration }\end{array}$ & $\begin{array}{c}\text { Removal efficiency } \\
(\%)\end{array}$ & $\begin{array}{c}\text { Effluent } \\
\text { concentration }\end{array}$ & $\begin{array}{c}\text { Removal efficiency } \\
(\%)\end{array}$ \\
\hline & & average & & average & \\
\hline COD Total & $1186(272)$ & $348(62)$ & 69.61(7.4) & $540(95)$ & $53.23(9.2)$ \\
\hline Suspended & $767(162)$ & 209(43) & $71.95(7)$ & $339(57)$ & $53.71(12)$ \\
\hline Colloidal & 111(76) & $18(7)$ & $77.08(14)$ & $22(15)$ & $78.11(12)$ \\
\hline Dissolved & $308(83)$ & 121(19) & $54.92(9)$ & $179(50)$ & $45.36(9)$ \\
\hline VFA as COD & $110(25)$ & $15(16)$ & $88.19(9)$ & 21(13) & $81.71(10)$ \\
\hline $\mathrm{NH}_{4}^{+}$as $\mathrm{N}$ & $84(4.9)$ & $80.12(17.8)$ & $-0.06(13.83)$ & $83.15(6.4)$ & $1.18(4.79)$ \\
\hline $\mathrm{PO}_{4}{ }^{3-}$ as $\mathrm{P}$ & $14.3(1.48)$ & $12.3(1.8)$ & $13.79(9.5)$ & $10.8(0.95)$ & $23.69(8.5)$ \\
\hline TSS & $1125(631)$ & $44.7(29)$ & $94(4.9)$ & $58.7(73)$ & $95(4.5)$ \\
\hline Faecal coliform & $\begin{array}{l}8.40 \mathrm{E}+09 \\
(4.5 \mathrm{E}+09) \\
\end{array}$ & $\begin{array}{c}3.37 \mathrm{E}+07 \\
(2.51 \mathrm{E}+07))\end{array}$ & $99.33(0.7)$ & $\begin{array}{c}3.80 \mathrm{E}+07 \\
(2.35 \mathrm{E}+07)\end{array}$ & $99.16(1.1)$ \\
\hline Tair & $29.42(2)$ & & & & \\
\hline Patm. & $0.923(0.008)$ & & & & \\
\hline
\end{tabular}

Standard deviations are shown in parenthesis; all parameters are in $\mathrm{mg} / \mathrm{L}$ except: faecal coliform: $\mathrm{CFU} / 100 \mathrm{ml}$; ambient air temperature: ${ }^{\circ} \mathrm{C}$; atmospheric pressure: atm. 


\subsection{Sludge profile}

The course of sludge bed development during the whole period of operation is depicted in Figure 3. The results clearly reveal a stable sludge bed development and rather stable sludge hold up in both reactors. The quantity of sludge in the sludge bed of the UASB-septic tank is more than the AH-septic tank sludge bed (see Table 4). This might be the main reason that the UASB-septic tank had performed better than the AH-septic tank. The sludge stability of both reactors assessed during the cold period was rather poor with $68 \%$ and $66 \%$ for respectively the UASB-septic tank and AH-septic tank. However, the results presented in Figure 3 clearly show an apparent better sludge stabilisation trend expressed as VS/TS ratios in the UASBseptic tank as compared with the AH-septic tank. The VS/TS ratio of sludge in the UASBseptic tank and the AH-septic tank were reduced respectively from 72(7.55) and 71(3.5) during the first period of operation, viz. The cold period, to 62(6) and 66(3.8) during the subsequent hot period. According to Wang [18] a (VS/TS) ratio of $63 \%$ can be considered a well-stabilized sludge. The excess sludge in both reactors over the whole period of operation was marginal.

\subsection{Hydrolysis, Acidification and Methanogenesis}

The percentage of COD hydrolysis $(H)$, acidification $(A)$ and methanogenesis $(M)$ in the UASB-septic tank assessed over the last 50 days of operation, viz. after 6 months of starting up the reactor, were respectively 29.3(12.7), 29.6(8.2) and 35.7(8.6). Those results are remarkably higher than the $\mathrm{H}, \mathrm{A}$ and $\mathrm{M}$ reported by Al-Shayah and Mahmoud [6] who also operated UASB-septic tank at the same wastewater treatment plant during the hot period of the former year. The difference is postulated to the better quality of the inoculums sludge used in this investigation. In this research, the reactors were inoculated with well adopted sludge brought from UASB-septic tanks that had been in operation for more than a year, while AlShayah and Mahmoud [6] inoculated the UASB-septic tanks with sludge from a cesspit. The achieved rather high percentage of methanogenesis indicates the stabilisation of accumulated sludge. Moreover, the results clearly reveal that the hydrolysis was limiting the overall conversion of organic matter to methane as the effluent contained a low amount of CODdis and VFA (see Table 3). The occurrence of methanogenic conditions is crucial for enhancement of lipids hydrolysis and acidification which is also affected by the degree of methanogenesis [19]. The VFA/CODdis had remarkably reduced from $40 \%$ in the influent to $12 \%$ in the effluent of both reactors, with a substantial decrease of VFA concentration in the effluent.
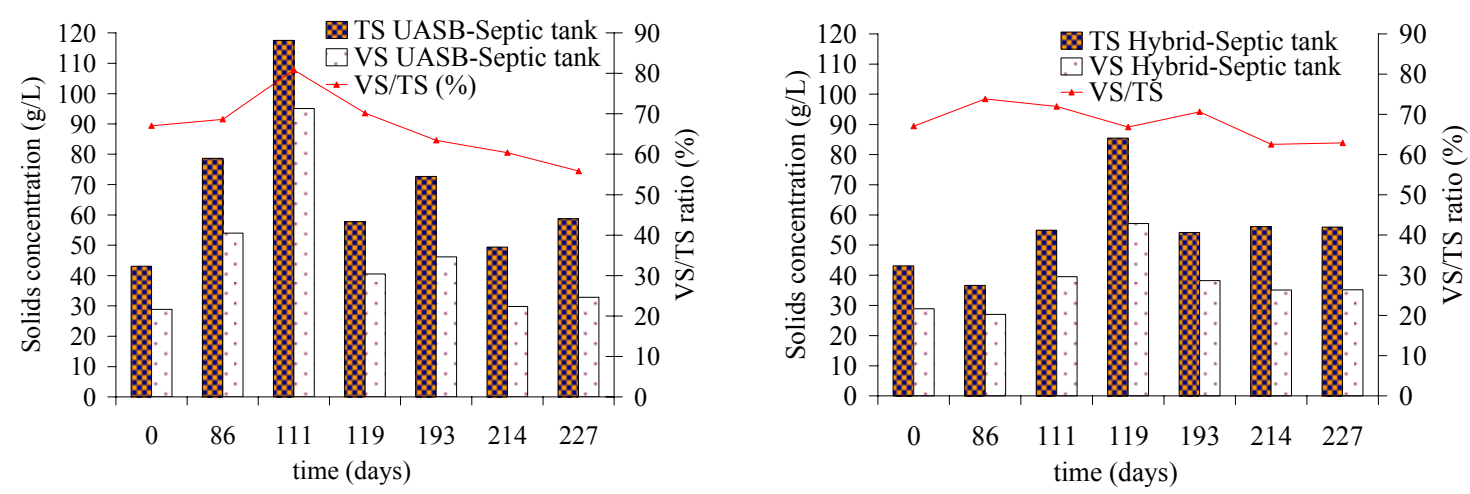

Figure 3. Course of sludge bed development in a UASB-septic tank and Anaerobic-Hybridseptic tank reactors treating domestic sewage. Solids concentration at days 0 stands for inoculum 
Table 4. Average VS, TS, and VS/TS ratios of the sludges retained in the UASB-septic tank and Hybrid-septic tank over the whole period of operation (day 0 - day 227)

\begin{tabular}{llll}
\hline & TS & VS & VS/TS \\
\hline UASB-septic tank & $68.28(25)$ & $46.75(23.19)$ & $66.63(8.01)$ \\
Hybrid-septic tank & $55.19(15.34)$ & $37.31(9.88)$ & $67.97(4.37)$ \\
\hline
\end{tabular}

Standard deviations are shown in parenthesis

\subsection{Final discussion}

The researched two reactors had performed rather equally well during the first period of operation coinciding the cold period of the year. But this trend was significantly changed during the subsequent hot period. During the latter period, the UASB-septic tank achieved significantly better CODtot removal efficiency as compared to the AH-septic tank of respectively 65 and 54\%. This result was rather surprising as it disagrees with our hypothesis that the packing media will enhance the removal efficiency. The more thorough analysis of the distinguished COD fractions removal efficiencies revealed that the CODss removal efficiency was the only significantly better removed COD fraction in the UASB-septic tank in comparison with the AH-septic tank. This might be due to accumulation of CODss beneath the packing media during the first period of operation which probably had started to erupt gradually during the subsequent hot period. Moreover, short circuiting and dead zones are popular drawbacks of the AH reactors. This was clear from the rather lower sludge content of the AH reactor in comparison with the UASB-septic tank. Wu et al. [20] found that increasing the packing ratio in $\mathrm{AH}$ reactors increases the by-pass flow rate due to short- circuiting and the dead space volume. They also reported that the sludge bed height decreased with increasing the packing ratio. Interestingly they also showed that the packing ratio did not cause much difference on the reactors performance at low organic loading rates (OLR) of 1 and $2 \mathrm{gCOD} / 1$.d which are higher than the imposed OLR to the here investigated UASBseptic tank and AH-septic tank.

The performance of the UASB-septic tank after several months of operation, viz. during the hot half of the year, was better than the formerly attained removal efficiencies in UASB-septic tanks operated at 2 and 4 days HRT of respectively $54 \%$ and $58 \%$ over the first year of operation when the reactors were operated during the hot half of the year in Palestine [6]. This strongly indicates that the inoculum quality is of vital importance to attain the maximum achievable performance of the UASB-septic tank reactors. During the first period of operation, viz. the cold period of the year, the attained removal efficiencies in the UASBseptic tank and AH-septic tank were in the range of results attained during the cold half of the year by Al-Jamal and Mahmoud [1] of 51\% and 54\% at 2 and 4 days HRT, respectively. Worth mentioning that the here researched UASB-septic tank was monitored over the coldest three months of the year which indicates better process performance as compared with the results reported by Al-Jamal and Mahmoud [1]. This proves the reliability of the anaerobic technologies for domestic sewage treatment in extreme situation of high strength and temperature fluctuation that was questioned in literature [21]. It is most likely that the performance of the reactor will improve further over the coming years of operation when more sludge is accumulated in the reactor. On the other hand, the very low sludge production implies that the costs for sludge handling associated with sewage treatment would be reduced dramatically by using UASB-septic tank. Moreover, the operational requirements of the system are quite minimal which makes the system very attractive for decentralised sanitation. 


\section{CONCLUSIONS AND RECOMMENDATIONS}

The performance of the UASB-septic tank reactor was substantially improved by starting up the reactor with well adopted anaerobic sludge. The UASB-septic tank reactor is more efficient as compared to the $\mathrm{AH}$-septic tank reactor for treating concentrated sewage with high solids content. Mean removal efficiencies for CODtot in the UASB-septic tank and AH-septic tank during the first period of operation, viz. the cold period, and after long period of operation, viz. hot period, of the research were respectively "50.07(14.7) and 47.87(15.1)" and "65.78(8.2) and 54.73(7.9)", respectively. The difference in the performance of the UASB-septic tank and AH-septic tank was significant after rather long period of operation. The difference in the CODtot removal efficiency was mainly due to the better CODss removal efficiencies in the UASB-septic tank reactor as compared to the AH-septic tank reactor. The achieved mean removal efficiencies during the last 50 days of operation for CODtot, CODss, CODco and CODdis in the UASB-septic tank and the AH-septic tank were "70, 72, 77 and $55 \%$ " and 53, 54, 78 and 45\%" respectively.

\section{ACKNOWLEDGEMENTS}

The authors acknowledge the Dutch Government (DGIS) for financial support through UNESCO-IHE Global Partnership for Water Education and Research (PoWER).

\section{REFERENCES}

[1] Al-Jamal, W., Mahmoud, N., 2009. Community onsite treatment of cold strong sewage in a UASB-septic tank. Bioresour. Technol. 100(3), 1061-1068.

[2] Zeeman, G., van Lier, J. B., Lettinga, G., 2000. The role of anaerobic treatment at community and house on-site treatment of domestic waste (water). Effect of collection and transport systems. In: Proceedings of the Technical Expert consultation on appropriate and innovative wastewater management for small communities in EMR countries. WHO/CEHA, Amman, Jordan, November 6-9, 2000.

[3] Lettinga, G., van Knippenberg, K., Veenstra, S., Wiegant, W., 1991. Final report "Upflow Anaerobic Sludge Blanket (UASB) low-cost sanitation project in Bandung, Indonesia. IHE, Delft, Agricultural University, Wageningen, St. Borromeus Hospital, Bandung, Indonesia.

[4] Bogte, J. J., Breure, A. M., van Andel, J. G., Lettinga, G., 1993. Anaerobic treatment of domestic wastewater in small scale UASB reactors. Wat. Sci. and Technol. 27(9), 75-82.

[5] Lettinga, G., de Man, A., van der Last, A. R. M., Wiegant, W., van Knippenberg, K., Frijns, J., van Buuren, J. C. L., 1993. Anaerobic treatment of domestic sewage and wastewater. Wat. Sci. Technol. 27(9), 67-73.

[6] Al-Shayah, M., Mahmoud, N., 2008. Start-up of an UASB-septic tank for community onsite treatment of strong domestic sewage. Bioresour. Technol. 99(16), 7758-7766.

[7] Mahmoud, N., Amarneh, M. N., Al-Sa'ed, R., Zeeman, G., Gijzen, H., Lettinga, G., 2003. Sewage characterisation as a tool for the application of anaerobic treatment in Palestine. Environ. Pollut. 126(1), 115-122.

[8] Halalsheh, M., Sawajneh, Z., Zu'bi, M., Zeeman, G., van Lier, J., Fayyad, M., Lettinga, G., 2005. Treatment of strong domestic sewage in a $96 \mathrm{~m}^{3}$ UASB reactor operated at ambient temperatures: two-stage versus single-stage reactor. Bioresour. Technol. 96, 577585. 
[9] Show, K. Y., Wang, Y., Foong, S. F., Tay, J. H., 2004. Accelerated start-up and enhanced granulation in upflow anaerobic sludge blanket reactors. Wat. Res. 38, 2293-2304.

[10] Calli, B., Mertoglu, B., Roest, K., Inanc, B., 2006. Comparison of long-term performances and final microbial compositions of anaerobic reactors treating landfill leachate. Bioresour. Technol. 97, 641-647.

[11] Álvarez, J. A., Ruiz, I., Gómez, M. Presas, J., Soto, M., 2006. Start-up alternatives and performance of an UASB pilot plant treating diluted municipal wastewater at low temperature. Bioresour. Technol. 97, 1640-1649.

[12] Büyükkamaci, N., Filibeli, A., 2002. Concentrated wastewater treatment studies using an anaerobic hybrid reactor. Process Biochem. 38, 771-775.

[13] Elmitwlli, T. A., Sayed, S., Groendijk, L., van Lier, J., Zeeman, G., Lettinga, G., 2003. Decentralised treatment of concentrated sewage at low temperature in a two-step anaerobic system: two upflow-hybrid septic tanks. Wat. Sci. Technol. 48(6), 219-226.

[14] APHA, 1995. Standard methods for the examination of water and wastewater. 18th edition, New York.

[15] Buchauer, K., 1998. A comparison of two simple titration procedures to determine volatile fatty acids in influents to wastewater and sludge treatment processes. Water $S A$, 24(1), 49-56.

[16] Mahmoud, N., 2002. Anaerobic pre-treatment of sewage under low temperature $\left(15^{\circ} \mathrm{C}\right)$ conditions in an integrated UASB-digester system PhD thesis, Department of Environmental Technology, Wageningen University, Wageningen, The Netherlands

[17] Metcalf \& Eddy, Inc., 2003. Wastewater Engineering: Treatment and Reuse, $4^{\text {th }}$ ed., McGraw Hill, New York.

[18] Wang, K., 1994. Integrated anaerobic and aerobic treatment of sewage. Ph.D. thesis, Department of Environmental Technology, Wageningen University, Wageningen, The Netherlands.

[19] Mahmoud, N., Zeeman, G., Gijzen, H., Lettinga, G., 2004. Anaerobic stabilization and conversion of biopolymers in primary sludge: effect of temperature and sludge retention time. Water Res., 38(4), 983-991.

[20] Wu, M., Wilson, F., Tay, J. H., 2000. Influence of media-packing ratio on performance of anaerobic hybrid reactors. Bioresour. Technol. 71, 151-157.

[21] Leitão, R. C., van Haandel, A. C., Zeeman, G., Lettinga, G., 2006. The effects of operational and environmental variations on anaerobic wastewater treatment systems: A review. Bioresour. Technol. 97, 1105-1118. 